\title{
New Prospects for Photodynamic Therapy of Bowen's Disease in Brazil
}

Keywords: Photodynamic therapy; Bowen's Disease; Follow up Abstract

The main treatment options for Bowen's Disease (BD) are cryotherapy, excision, 5-fluorouracil, radiotherapy and laser. However, the effectiveness of several therapies is uncertain. Photodynamic Therapy is an effective alternative that provides better cosmetic results than the standard treatment which is specially indicated in cases of initial and thin lesions with less than two centimeter in diameter. The untreated disease can progress to invasive squamous cell carcinoma. This technique was the standard treatment of Bowen's Disease in this study, using a pro-drug (methyl aminolevulinate, MAL, PDTPharma $^{\circledast}$, Cravinhos, São Paulo, Brazil) produced in Brazil and a device (LINCE ${ }^{\circledast}$, MMOptics, São Carlos, São Paulo, Brazil) approved by the National Health Surveillance Agency (ANVISA). Were treateda total of 32 lesions. The clinical response was determined 30 days after the second PDT session. The clinical response was associated with gender and location. The protocol developed in the project PDT Brazi is an efficient alternative to the BD treatment. The conclusion of study has shown the efficacy PDT with $84 \%$ of clearance of superficial BD and low recurrence rate.

\section{Introduction}

Bowen's disease (DB) also known as squamous cell carcinoma (SCC) in situ - was first described by Bowen in 1912 [1], is characterized by well-defined erythematous plaques. DB may progress into SCC $[2,3]$ in $3 \%$ to $5 \%$ of cases.

The prevalence of skin lesions has been reported in the upper limbs. However, they may appear as a periungual or subungual mass in palmar, genital and perianal áreas [4,5]. In [6] a 12-year-old patient with BD was successfully treated with two sessions of PDT on the periungual area. BD's lesions presents atypical keratinocytes similar to actinic keratosis (AK), however differs in epidermis layer location [7] with potential for skin invasion.

Chemotherapy, excision, photodynamic therapy (PDT) and surgery are treatment options for $\mathrm{BD}$. The cryosurgery is widely used and the wound healing process can result in hypochromic or atrophic scar [8]. According to Morton et al. the cryosurgery has been associated to complications of ulceration and infection, which not been observed in PDT [9].

PDT is a treatment technique easy, quick and safe that uses light, photosensitive compounds and oxygen in the treatment of tumors. PDT has proven effective in skin cancer treatment with good aesthetic results [10]. Studies as performed by Won suggest that PDT using different concentrations of ALA is a noninvasive method to treat BD with scar-free contracture [11]. PDT using topical aminolevulinic acid (ALA) and its derived compounds is an effective treatment for Bowen disease [12]. PDT was unaffordable in Brazil due to export of equipment and drug, however with national product, in August 2016, M-ALA (PDT Pharma) cost \$ 102 less than

\section{Journal of}

\section{Clinical \& Investigative} Dermatology

Beatrix Zink ${ }^{1}$, Kate C. Blanco ${ }^{2^{\star}}$, Natalia M. Inada ${ }^{2}$, Silvio Govone $^{3}$ and Vanderlei S. Bagnato ${ }^{2}$

${ }^{\prime}$ Federal Hospital of Bonsucesso, Rio de Janeiro, RJ, Brazil

${ }^{2}$ São Carlos Institute of Physics, University of São Paulo, São Carlos, SP, Brazil

${ }^{3}$ Department of Statistics, Applied Mathematics and Computers at the Universidade Estadual Paulista, Rio Claro, SP, Brazil

*Address for Correspondence

Kate Cristina Blanco, São Carlos Institute of Physics, University of São Paulo, São Carlos, SP, Brazil, Tel: +55(16) 3373-9810, Fax: 3373-9811;

E-mail: blancokate@gmail.com

Submission: 18 May, 2016

Accepted: 14 September, 2016

Published: 20 September, 2016

Copyright: $\odot 2016$ Zink B, et al. This is an open access article distributed under the Creative Commons Attribution License, which permits unrestricted use, distribution, and reproduction in any medium, provided the original work is properly cited.

standard cream - PDT.

The pain is side effect expected that may cause limitations of treatment. In order to analyze PDT efficacy of BD using Brasilian product and equipment, a clinical study was developed using variables such as characteristics of lesion and patient, pain and follow up time.

\section{Materials and Methods}

\section{Participants}

The Ethics Committee approved for protocol of study. The research was conducted in compliance with current Brazilian regulations. All diagnosed patients with BD were referred for Federal Hospital of Bonsucesso. The inclusion criteria were: patients aged above 18 years and histopathological confirmation of disease. The exclusion criteria were pregnancy, lactation and severe malignant disease. The patients diagnosed with the disease were invited by the medical doctor responsible (first author BZ) with consent from the patient to be a part of this study.

\section{Study protocol}

Each lesion was cleaned with chlorhexidine solution before of curettage. After of curettage, MAL (PDTPharma ${ }^{\circledR}$ ) at $20 \%$ in cream was applied to the lesion with a layer of $0.3 \mathrm{~cm}$ and border of $2 \mathrm{~cm}$. The curettage assisted in entry of the drug into deeper layers of lesions. The lesion was covered with aluminum foil, protect from ambient light. After three hours of application of MAL cream, the lesion was irradiated with $630 \mathrm{~nm}, 125 \mathrm{~mW} / \mathrm{cm}^{2}$ and $150 \mathrm{~J} / \mathrm{cm}^{2}$ (LINCE MM Optics).

The analysis of pain intensity was measured by verbal numerical scale in 20 minutes of illumination: little (intensity 1 to 3 ); moderate (intensity 4 to 6); severe (intensity 7 to 10 ).

The second session was realized after seven days from first session, following the same protocol. The patients returned after 30 days for 
Citation: Zink B, Blanco KC, Inada NM, Govone S, Bagnato VS. New Prospects for Photodynamic Therapy of Bowen's Disease in Brazil. J Clin Investigat Dermatol. 2016;4(2): 4.

ISSN: $2373-1044$

Table 1: Histopathological analysis after treatment and clinical evaluation after three, six, nine and twelve months from treatment.

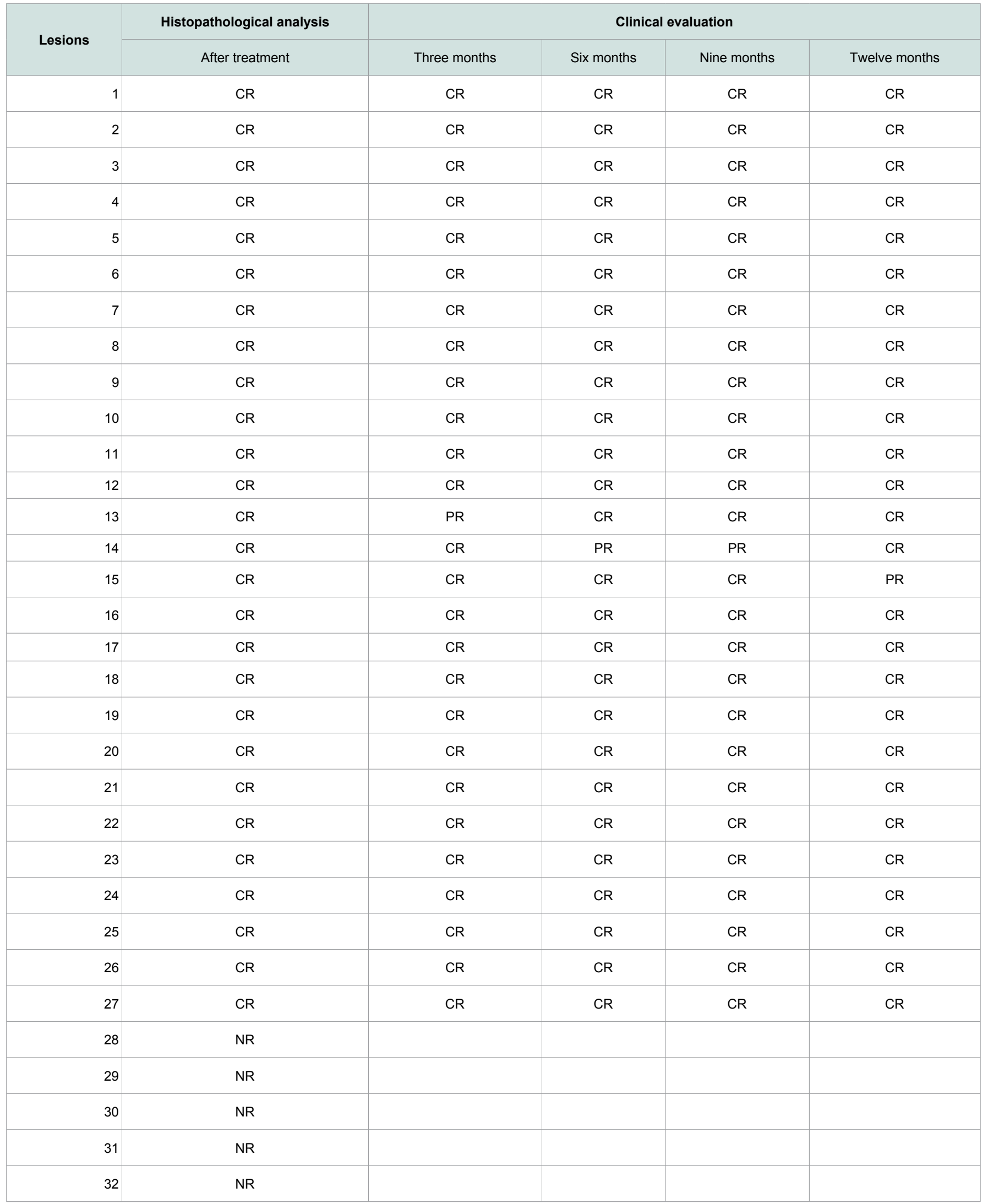

BD: Bowen Disease; CR: Complete Response; PR: Partial Response; NR: Non-Response 


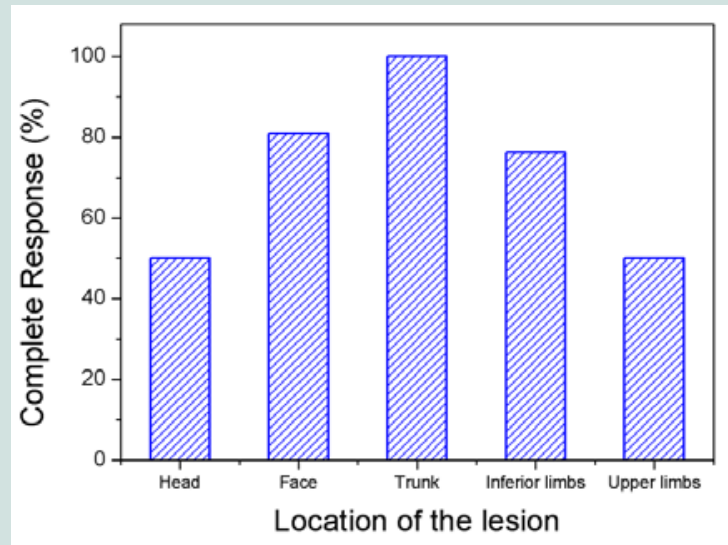

Figure 1: Results of treatment (non-injured and prevalent lesion) of BD classified by body region.

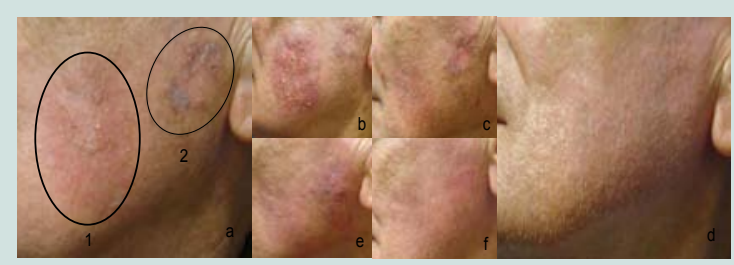

Figure 2: Aesthetic results and absence of 8 lesions after PDT in the face of a patient.

follow-up of treatment, performing a clinical and histopathological evaluation (Table 1).

\section{Statistical analysis}

The Wilcoxon rank sum test was used for comparison continuous variables. Results were considered significant at significance level $p<$ 0.05 . Multiple logistic regression tests were performed to determine a model that represent not cured in PDT.

\section{Results}

The therapeutic effect of PDT was analyzed according to safety, response to treatment, tolerability. In this study performed with PDT, it was observed a high cure rate of $84.4 \%$.

\section{Patient variable}

The study involved 24 patients ( 12 women and 12 men) with age ranged from 50 to 87 years with 32 treated lesions. Since, 27 of 32 lesions showed complete response to treatment. Clinical and histological evaluations were performed before and after the BD's treatment to confirm this response and recurrences.

\section{Anatomical location of lesion}

Variables of protocol as lesion and patient characteristics may influence on the success of treatment. The Figure 1 shows the response of therapy considering the anatomical location of lesions.

\section{Aesthetic outcome}

Figure 2 shows the follow-up after the treatment of BD lesions ( 1 and 2) on patient's face: before treatment (a); lesion 1 with a followup of 30 (b) and 60 (c) days; lesion 2 with a follow up of 30 (e) and 60 days (f); aesthetic result (d) of multiple lesions were observed after 90 days from the treatment.

\section{Side effect}

Figure 3 shows the pain score during 20 minutes of illumination of PDT of lesions, including first and second session of treatment. The second session was realized after sevendays from first session, following the same protocol.

The pain was measured by verbal numerical scale in 20 minutes of illumination: little (intensity 1 to 3 ); moderate (intensity 4 to 6 ); severe (intensity 7 to 10 ). The highest average of pain described by patients was 4.9 , indicating the moderate pain. The painful was higher in the first session than one-second session, with increase of sensation during the second session during 20 minutes.

\section{Follow up time}

The recurrence of a disease is due to its reappearance or a symptom after a curing period, however any lesion in the same place of treated was considered on Figure 4. This short-term follow-up study of recurrence of BD lesions after PDT showed that the risk of second malignancies was $0 \%$ in twelve months, with appearance only of $\mathrm{AK}$ and solar elastosis (12\%) after treatment (Figure 4).

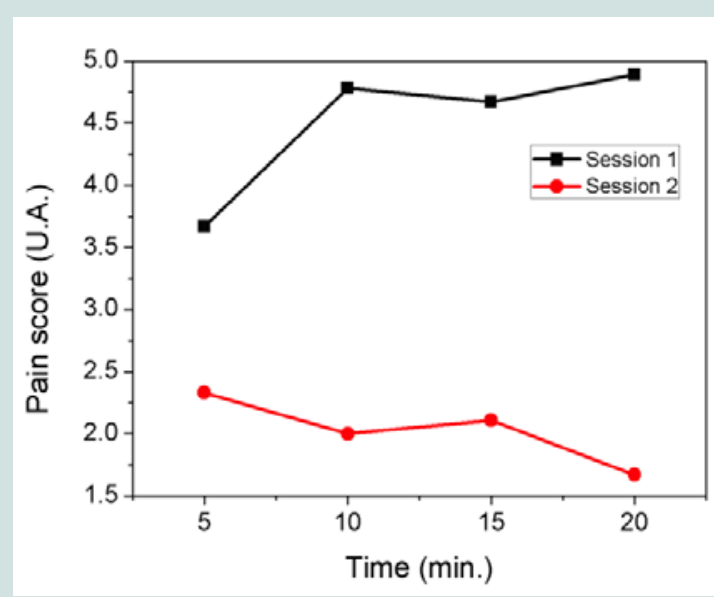

Figure 3: Painful during 20 minutes of PDT.

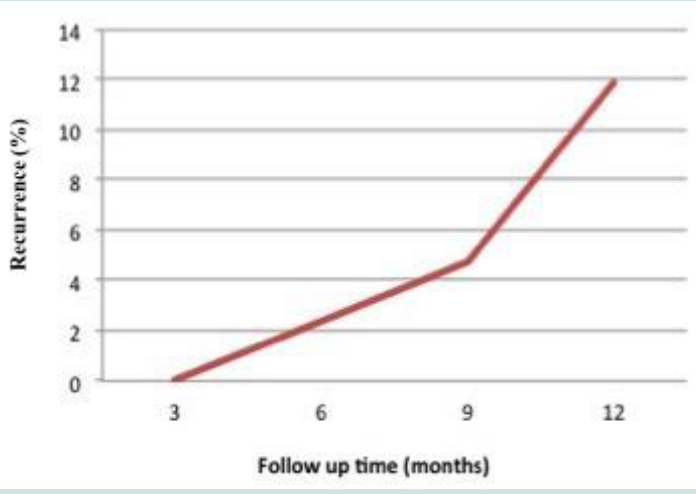

Figure 4: Follow up of BD's PDT 
Whereas the recurrences in following treatment of skin cancer (non melanoma) occurs in first year.

\section{Statistical analysis}

There was no significant difference between gender in the proportion of cured $(\mathrm{p}=0.185>0.05)$ in the binomial test. The response to treatment is an indicator of therapeutic effect of photodynamic action on BD. The Eq. 1 (EA1) represents an empirical model obtained for response of $\mathrm{BD}$ to PDT, in function of age $(\mathrm{P} \leq$ 0.05 ) determined using a multiple logistic regression test.

Complete Response $(\%)=\left[1-\frac{1}{1+\varepsilon^{3.3110-0.0255 \times A g r(y e a r s)}}\right] \times 100$

The results show that the age (independent variable) had a significant effect in complete response of treatment, as demonstrated by the equation 1 . The decay factor of complete response increases with age of patients with BD. Patients of advanced age often present outcome of treatment compromised by deficiency of immune system and factors of comorbid conditions.

\section{Discussion}

However, the innovation of this treatment is the use of pro-drug M-ALA synthesized by national company (PDT Pharma). After $3 \mathrm{~h}$ from application of cream (20\% m-ALA) occurs the metabolic conversion of pro-drug into porphyrin which accumulates in lesions and causes a cytotoxic process in photodynamic action.

The most common locations of $\mathrm{BD}$ is areas with high sun exposure [4]. However, the localization of BD's lesions shows no respect with cure rate, considering the difficulty of penetration of light into lesions with difficult anatomic location [14]. The geometry of lesion on skin modifies the absorption of light. Incident light in the $\mathrm{BD}$ presents different behavior of absorption in relation to skin.

The extensive injuries on the face present difficulties in treatment. The study by Whitehurst $\mathrm{C}$, et al. eighty-five patches of $\mathrm{BD}$ received the same treatment for large and multiple lesions with clearance of $94 \%$ [12]. Whereas one of the main advantages of PDT are the low level of invasiveness and excellent cosmetic results [2].

Painful in PDT may be caused by sensitivity to photosensitizer and light due to stimulation of nerve endings and inflammatory reactions. The potential tissue damage that destroys cells of lesions may cause pain during and after the illumination of skin. The study of pain score in PDT of BD is important for optimization of method. Lower number of diseased cells may cause less inflammatory reaction in PDT in second session.

It was possible to accompany the follow up time of 12 months of treatment with clinical evaluation every three months. Which presents absence of $\mathrm{BD}$, however there was appearance of other premalignant lesions.

\section{Conclusion}

This treatment was unaffordable in Brazil due to export of equipment and drug, but now become feasible due to accessibility of national products after be part in a multicenter study. This study treated BD lesions in Federal Hospital of Bonsucesso - RJ and concluded that PDT is an important therapeutic option for this disease. Which showed the efficacy of PDT with until $88.4 \%$ of clearance of BD.

\section{References}

1. Kossard S, Rosen R (1992) Cutaneous bowen's disease. J Am Acad Dermatol 27: 406-410.

2. Neubert T, Lehmann $P$ (2008) Bowen's disease - a review of newer treatment options. Ther Clin Risk Manag 4: 1085-1095.

3. Diepgen TL, Mahler V (2002) The epidemiology of skin cancer. Br J Dermatol 146 Suppl 61: 1-6.

4. Hansen JP, Drake AL, Walling HW (2008) Bowen's disease: a four-yea retrospective review of epidemiology and treatment at a university center. Dermatol Surg 34: 878-883.

5. Gordon KB, Roenigk HH, Gendleman M (1997) Treatment of multiple lesions of Bowen disease with isotretinoin and interferon alfa. Efficacy of combination chemotherapy. Arch Dermatol 133: 691-693.

6. Hyun DJ, Seo SR, Kim DH, Yoon MS, Lee HJ (2016) Periungual bowen's disease in a 12-year-old boy treated with photodynamic therapy. Pediatric Dermatology 33: e82-e83.

7. Anwar J, Wrone DA, Kimyai-Asadi A, Alam M (2004) The development of actinic keratosis into invasive squamous cell carcinoma: evidence and evolving classification schemes. Clin Dermatol 22: 189-196.

8. Pimentel CB, Moraes AM, Cintra ML (2014) Angiogenic effects of cryosurgery with liquid nitrogen on the normal skin of rats, through morphometric study. An Bras Dermatol 89: 410-413.

9. Morton CA, Whitehurst C, Moseley H, McColl JH, Moore JV, et al. (1996) Comparison of photodynamic therapy with cryotherapy in the treatment of bowen's disease. Br J Dermatol 135: 766-771.

10. Blanco KC, Inada NM, Salvio AG, Vollet-Filho JD, Bagnato VS (2016) Clinical photodynamic therapy review and the Brazilian experience. J Tumor 4: 386392.

11. Wong TW, Sheu HM, Lee JY, Fletcher RJ (2001) Photodynamic therapy for Bowen's disease (squamous cell carcinoma in situ) of the digit. Dermatol Surg 27: 452-456.

12. Morton CA, Whitehurst C, McColl JH, Moore JV, MacKie RM (2001) Photodynamic therapy for large or multiple patches of bowen disease and basal cell carcinoma. Arch Dermatol 137: 319-324.

13. Szeimies RM, Morton CA, Sidoroff A, Braathen LR (2005) Photodynamic therapy for non-melanoma skin cancer. Acta Derm Venereol 85: 483-490.

14. Babilas P, Schreml S, Landthaler M, Szeimies RM (2010) Photodynamic therapy in dermatology: state-of-the-art. Photodermatol Photoimmunol Photomed 26: 118-132.

\section{Acknowledgements}

The authors acknowledge the support provided by Brazilian Funding Agencies: BNDES (09.2.1458.1); FINEP; Capes; and grant 2013/07276-1 (CEPOF). We are also grateful to MM Optics and PDT Pharma. 